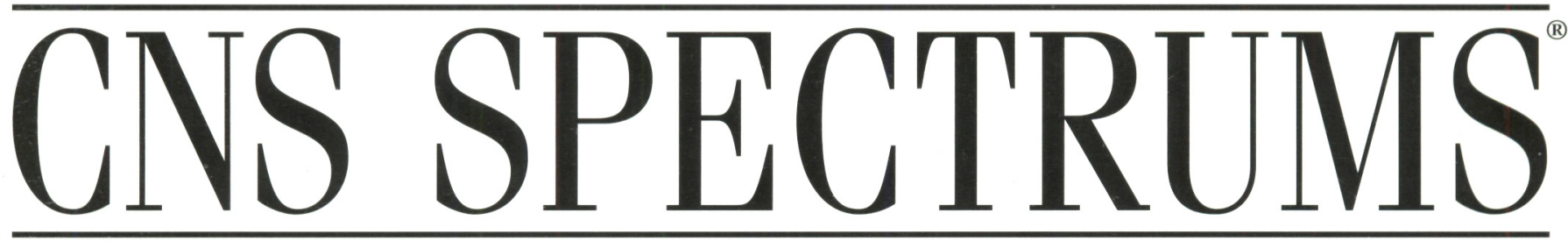

The International Journal of Neuropsychiatric Medicine

\title{
Medical Chronobiology in Psychiatry and Neurology
}

Circadian Rhythms in Medicine

M.H. Smolensky

Is Seasonal Affective Disorder a Disorder of Circadian Rhythms?

P.H. Desan and D.A. Oren

Melatonin Rhythm Abnormalities and Sleep Disorders in the Elderly I. Haimov

ORIGINAL RESEARCH

Gircadian Rhythm Sleep Disorders as a Possible Side Effect of Fluvoxamine H. Hermesh, H. Lemberg, J. Abadi, and Y. Dagan

\section{ORIGINAL RESEARCH}

The Effect of Smoking on Brainstem Auditory Evoked Potentials in Positive- and Negative-Symptom Schizophrenia A. Mubarak and A. Badawy

FIRST PERSON

The Rage to Know, the Rage to Teach, and the Rage to Heal: What Is the Proper Balance?

C.B. Nemeroff

THE NEUROLOGY OF BEHAVIOR

Towards a Neurology of Aesthetics

M. Trimble 


\section{You see it as maintaining cognitive}

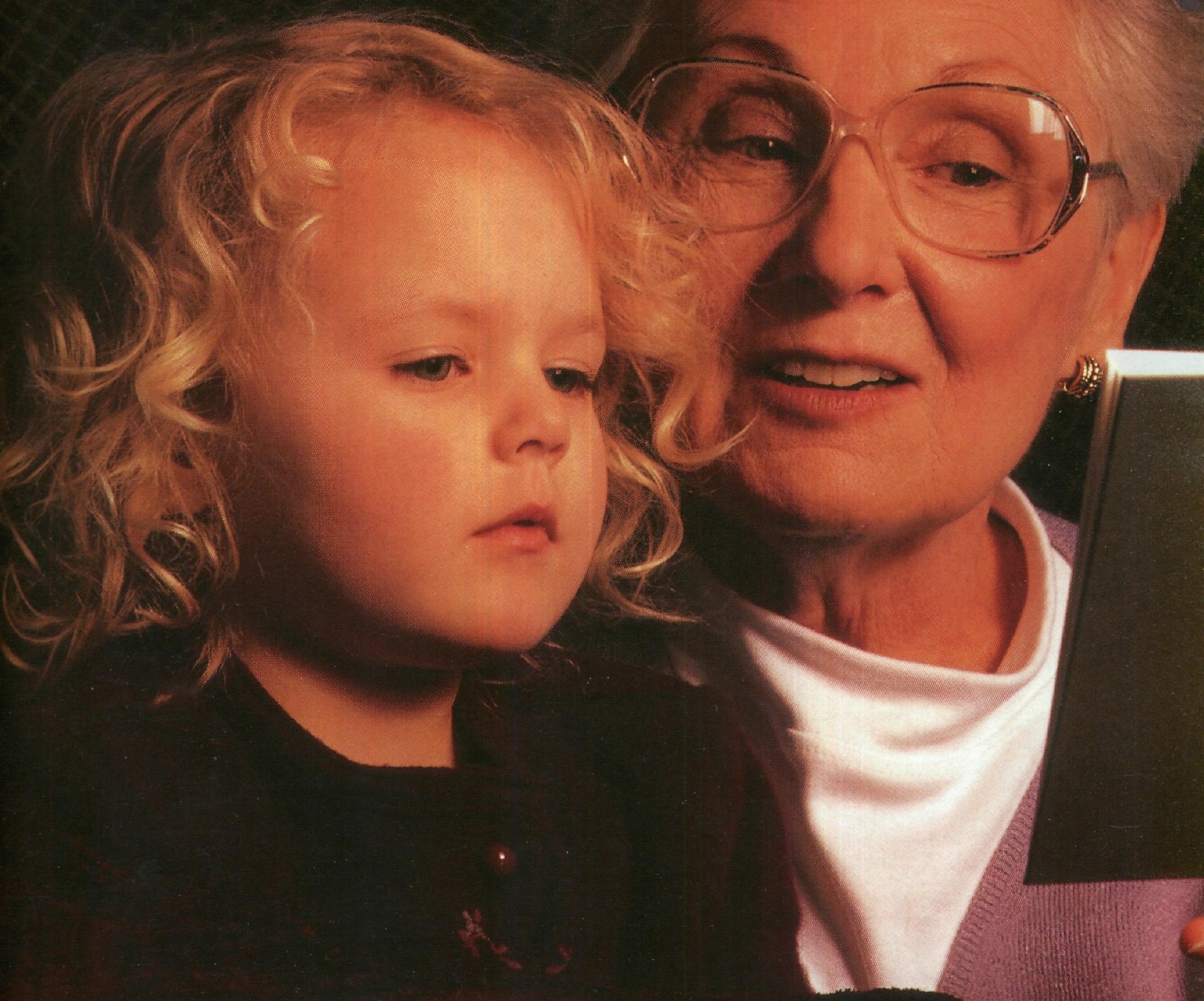

* Individual responses to ARICEPT ${ }^{\circledR}$ may include improvement, stabilization, or decline.

$\dagger$ The most common adverse events in pivotal clinical trials with ARICEPT $^{\circledR}$ were nausea, diarrhea, insomnia, vomiting, muscle cramps, fatigue, and anorexia. Pivotal clinical trials of ARICEPT $^{\oplus}$. have shown no increase, relative to placebo, in the incidence of either peptic ulcer disease or gastrointestinal bleeding. Nevertheless, cholinesterase inhibitors may be expected to increase gastric acid secretion. Therefore, patients (especially those at increased risk for developing ulcers - eg, having a history of ulcer disease, receiving concurrent nonsteroidal anti-inflammatory drugs) should be monitored closely for gastrointestinal bleeding. In pivotal clinical trials, syncopal episodes have been reported in association with $\mathrm{ARICEPT}^{\oplus}$ ( $2 \%$ vs $1 \%$ for placebo). 


\section{function.}

\section{She sees it as a bedtime story.}

ARICEPT ${ }^{\circledast}$. Helping to make a difference for people living with Alzheimer's

- Slows the worsening of symptoms*

- Proven to maintain cognition in placebo-controlled studies

- Well tolerated ${ }^{\dagger}$

- Proven safety profile

- Once-daily dosing

- 3 years of real-world use

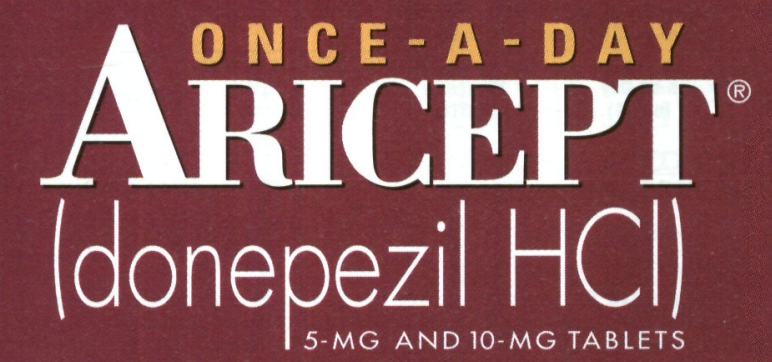

\section{THERAPY TO REMEMBER ${ }^{\mathrm{m}}$}

Please see brief summary of prescribing information on adjacent page. 


\section{0-Day Planner}

MEETINGS

DEADLINES

REMINDERS

July

Sunday

Monday

Tuesday

Wednesday

Thursday

Friday

Saturday

1

2

3

4

5

6

$7(-10)$

Independence

International

Day-USA

Neuropsychological

Society:

23rd Midyear Meeting,

Brasilia, DF, Brazil

(July 4-7)

contact:

Tel: 614.263 .4200

Fax: 614.263.4366

Focus on Epilepsy Vl: Treatment of Epileptic

Syndromes from

Molecular Targets to

Quality of Life:

Chateau Mont-Tremblet

QC, Canada

contact

Tel:514.933.0502

eriplus@total.net

\begin{tabular}{|c|c|c|c|c|}
\hline \multirow[t]{2}{*}{8} & 10 & $11(-15)$ & $12(-14)$ & 14 \\
\hline & $\begin{array}{l}2001- \\
\text { A Mind Odyssey: } \\
\text { Science and Caring: } \\
\text { London, UK } \\
\text { contact: } \\
\text { Tel: } 44.20 .72 .35 .23 .51 \times 142 \\
\text { mbraithwaite@ } \\
\text { rcpsych.ac.uk }\end{array}$ & $\begin{array}{l}\text { Annual Convention of } \\
\text { the National Alliance } \\
\text { for the Mentally III: } \\
\text { Washington, DC } \\
\text { contact: } \\
\text { Tel: } 800.950 .6264 \\
\text { Fax: } 703.524 .9094\end{array}$ & $\begin{array}{l}2001 \text { Conference of } \\
\text { the Stress and Anxiety } \\
\text { Research Society: } \\
\text { Majorca, Spain } \\
\text { contact: } \\
\text { Tel: } 34.971 .173 .038 \\
\text { dpsjpp0@ps.uib.es }\end{array}$ & \\
\hline
\end{tabular}

\begin{tabular}{|c|c|c|c|c|c|c|}
\hline \multirow[t]{2}{*}{15} & $16(-20)$ & 17 & $18(-21)$ & $19(-22)$ & $20(-23)$ & $21(-24)$ \\
\hline & $\begin{array}{l}\text { 18th Annual Summer } \\
\text { Symposium: } \\
\text { Difficult Personality } \\
\text { Disorder- } \\
\text { A Comprehensive } \\
\text { Treatment Approach, } \\
\text { Eastham, MA } \\
\text { contact: } \\
\text { Tel: } 800.926 .1232\end{array}$ & & $\begin{array}{l}\text { National Conference } \\
\text { on Autism: } \\
\text { San Diego, CA } \\
\text { contact: } \\
\text { Tel: } 301.657 .0881 \\
\text { thayes@ } \\
\text { autism-society.org }\end{array}$ & $\begin{array}{l}\text { 9th Annual Advanced } \\
\text { Topics in CT Scanning: } \\
2001 \text { Edition: } \\
\text { Lake Tahoe, NV } \\
\text { contact: } \\
\text { Tel: } 410.995 .2959 \\
\text { cmenet@jhmi.edu }\end{array}$ & $\begin{array}{l}\text { Advances in } \\
\text { Neurology: } \\
\text { St. Petersburg, FL } \\
\text { contact: } \\
\text { Tel: } 813.259 .0605 \\
\text { sbenbadi@ hsc.usf.edu }\end{array}$ & $\begin{array}{l}\text { 16th Mexican } \\
\text { Congress of } \\
\text { Neurological Surgery: } \\
\text { Puerto Vallarta, Mexico } \\
\text { contact: } \\
\text { Tel: } 52.55 .430 .013 \\
\text { smcirneu@dsi.com.mx }\end{array}$ \\
\hline $22(-27)$ & 23 & 24 & $25(-27)$ & 26 & $27(-29)$ & 28 (-Aug 1) \\
\hline $\begin{array}{l}\text { 26th Biennial } \\
\text { Congress } \\
\text { of the World } \\
\text { Federation for } \\
\text { Mental Health: } \\
\text { Vancouver, Canada } \\
\text { contact: } \\
\text { Fax: } 703.684 .5968\end{array}$ & $\begin{array}{l}\text { Mt. Sinai School } \\
\text { of Medicine: } \\
\text { Alzheimer's Disease, } \\
\text { Cancer, and the Search } \\
\text { for a Better Aspirin, } \\
\text { New York, NY } \\
\text { (July 22-23) } \\
\text { contact: } \\
\text { Tel: 212.241.6737 }\end{array}$ & & $\begin{array}{l}\text { National Institute of } \\
\text { Mental Health: } \\
\text { Preventing and Adapting } \\
\text { to HIV/AIDS, } \\
\text { Los Angeles, CA } \\
\text { contact: } \\
\text { Tel: } 301.443 .611 \\
\text { Fax: } 301.443 .9719\end{array}$ & & $\begin{array}{l}\text { World Events } \\
\text { Forum, Inc.: } \\
\text { Challenging Views of } \\
\text { Alzheimer's Disease, } \\
\text { Cincinnati, OH } \\
\text { contact: } \\
\text { Tel: } 7.737 .848 .134 \\
\text { contact@ } \\
\text { worldeventsforum.com }\end{array}$ & $\begin{array}{l}\text { 14th International } \\
\text { Congress on } \\
\text { Parkinson's Disease: } \\
\text { Helsinki, Finland } \\
\text { contact: } \\
\text { Tel: } 358.945 .421 .933 \\
\text { aira@congcreator.com }\end{array}$ \\
\hline
\end{tabular}

29

30

31 


\section{0-Day Planner}

\section{August}

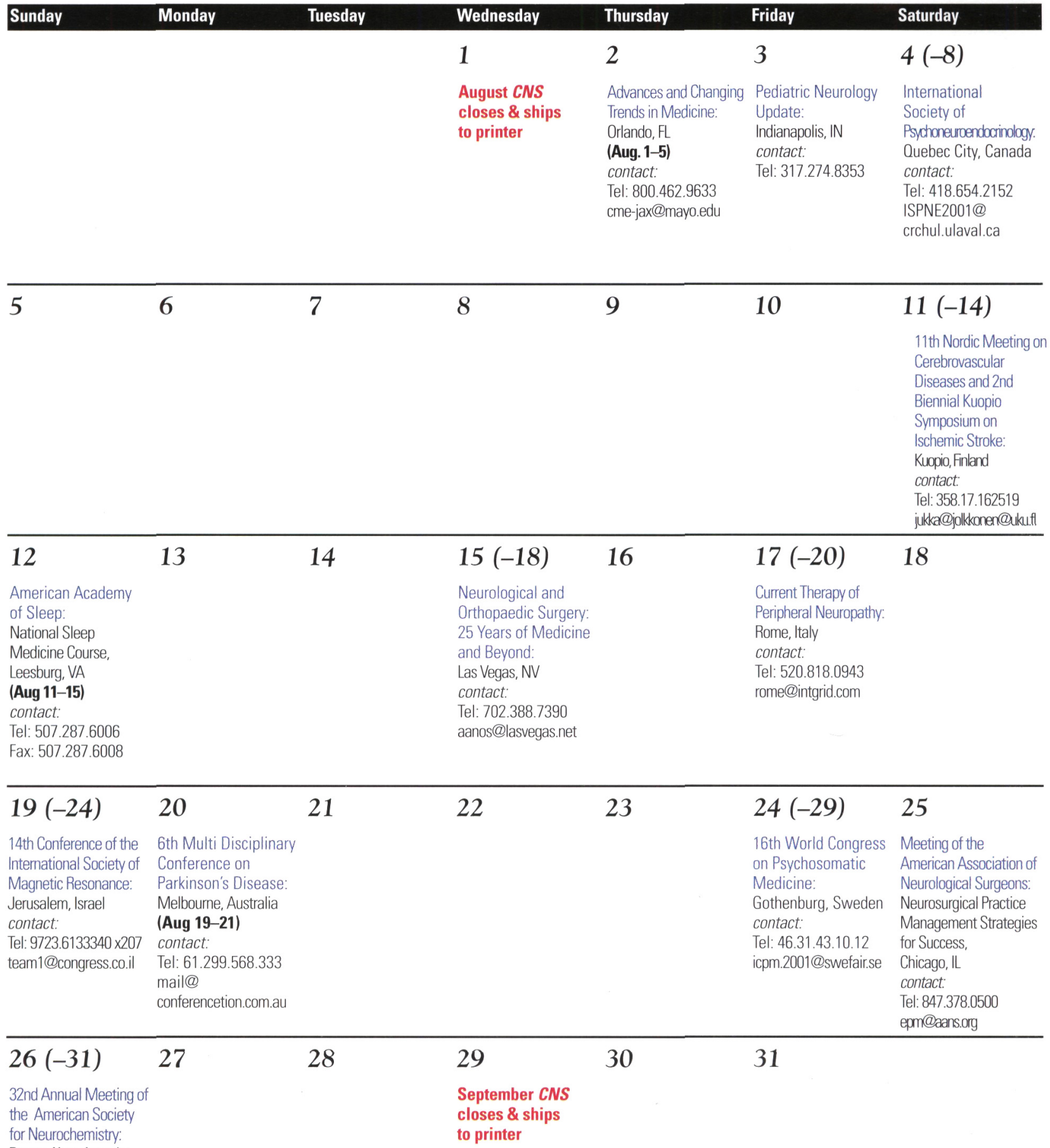

Buenos Aires, Aggentina

contact:

Tel: 352.271 .3383 
ARICEPT* (Donepezil Hydrochloride Tablets)

Brief Summary - see package insert for full prescribing information. INDICATIONS AND USAGE ARICEPT ${ }^{\star}$ is indicated for the treatment of mild to moderate dementia of the Alzheimer's type. CONTRAINDICATIONS ARICEPT is contraindicated in patients with known hypersensitivity to donepezil hydrochloride or to piperidine derivatives. WARNINGS Anssthes/g: ARICEPT ${ }^{\star}$ as a cholinesterase inhibitor is likely to exaggerate succinylcholine-type muscle relaxation during anesthesia. Cardlovascular Conditions: Because of their pharmacological action, cholinesterase inhibitors may have vagotonic effects on heart rate (e.g., bradycardia). The potential for this action may be particularly important to patients with "sick sinus syndrome" or other supraventricular cardiac conduction conditions. Syncopal episodes have been reported in association with the use of ARICEPT ${ }^{\star}$. Gastrolntestinal Condlions: Through their primary action, cholinesterase inhibitors may be expected to increase gastric acid secretion due to increased cholinergic activity. Therefore, patients should be monitored closely for symptoms of active or occult gastrointestinal bleeding, especially those at increased risk for developing uicers, e.g. those with a history of ulcer disease or those receiving concurrent nonsteroidal anti-inilammatory drug s (NSAIDS). Clinical stuties of ARICEPT ${ }^{-}$have shown no increase, relative to placebo, in the incidence of either peptic ulcer disease or gastrointestinal bleeding. ARICEPT", as a predictable consequence of its pharmacological properties, has been shown to produce diarrhea, nausea and vomiting. These effects, when they occur, appear more frequently with the $10 \mathrm{mg} / \mathrm{day}$ dose than with the $5 \mathrm{mg} /$ day dose. In most cases, these effects have been mild and transient, sometimes lasting one to three weeks, and have resolved during continued use of ARICEPT. Gentfourinary Although not observed in clinical trials of ARICEPT ${ }^{*}$, cholinomimetics may cause bladder outllow obstruction. Nourological Condhions: Seizures: Cholinomimetics are believed to have some potential to cause generalized convulsions. However, seizure activity also may be a manifestation of Alzheimer's Disease. Puimonary Condhions: Because of their cholinomimetic actions, cholinesterase inhibitors should be prescribed with care to patients with a history of Profelns: Drug displacement studies have been performed in vitro between this highly bound drug (96\%) and other drugs such as furosemide, digoxin, and warfarin. ARICEPT at concentrations of $0.3-10 \mu \mathrm{g} / \mathrm{mL}$ did not affect the binding of furosemide $(5 \mu \mathrm{g} / \mathrm{mL}$ ), dipoxin (2 no/mL), and warlarin $(3 \mu \mathrm{g} / \mathrm{mL})$ to human albumin. Similarly, the binding of ARICEPT ${ }^{\circ}$ to human albumin was not affected by furosemide, digoxin, and warlarin. Efiect of ARICEPP on the Motabolism of other Orugs: No in vivoclinical trials have investigated the effect of ARICEPT on the clearance of drugs Motabolism of Other Orugs: No in vivo clinical trials have investigated the effect of ARICEPT on the clearance of drugs metabolized by CYP $3 A 4$ (e.g. Cisapride, terfenadine) or by CYP 2D6 (e.g. imipramine). However, in vitro studies show a
low rate of binding to these enzymes (mean $\mathrm{K}_{\mathrm{i}}$ about $50-130 \mu \mathrm{M}$ ), that, given the therapeutic plasma concentrations of low rate of binding to these enzymes (mean $K_{i}$ about $50-130 \mu \mathrm{M}$ ), that, given the therapeutic plasma concentrations of donepezil (164 nM), indicates little like lhood of interference. Whether ARICEPT has any potential for enzyme induction is not known. EHact of Other Drugs on the Motabofism of ARICEPTP: Ketoconazole and quinidine, inhibitors o is not known. Inducers of CYP 206 and CYP $3 \mathrm{A4} 4$ (e.9. phenytoin, carbamazepine, dexamethasone rifampin and phenobarbitai) could increase the rate of elimination of ARICEPT. Use with Anticholinergics: Because of their mechanism of action, cholinesterase inhibitors have the potential to interfere with the activity of anticholinergic medications. Use with cholinomimetlos and Other Chollnostoress inhibitors: A synergistic effect may be expected when cholinesterase inhibitors are given concurrently with succinylchaline, similar neuromuscular blocking agents or cholinergic agonists such as bethanechol. Carcinogenesis, Mutagenesis, Impairment of Fertlity Carcinogenicity studies of agonists such as bethanechol. Carcinogenesis, Mutagenesis, Impairment of Fert
donepezil have not been completed. Donepezil was not mutagenic in the Ames reverse donepezil have not been completed. Donepezil was not mutagenic in the Ames reverse mutation assay in bacteria. In the chromosome aberration test in cultures of Chinese hamster lung (CHL) cells, some clastogenic effects were observed. Donepezil was not clastogenic in the in vivo mouse micronucleus test. Donepezil had no effect on fertility in rats at doses up to $10 \mathrm{mg} / \mathrm{kg} / \mathrm{day}$ (approximately 8 times the maximum recommended human dose on a $\mathrm{mg} / \mathrm{m}^{2}$ basis). Pregnancy Pregnancy Category C: Teratology studies conducted in pregnant rats at doses up to $16 \mathrm{mg} / \mathrm{kg} / \mathrm{day}$ (approximately 13 times the maximum recommended human dose on a $\mathrm{mg} / \mathrm{m}^{2}$ basis) and in pregnant rabbits at doses up to $10 \mathrm{mg} / \mathrm{kg} /$ day (approximately 16 times the maximum recommended human dose on a $\mathrm{mg} / \mathrm{m}^{2}$ basis) did not disclose any evidence for a teratogenic potential of donepezil. However, in a study in which pregnant rats were given up to $10 \mathrm{mg} / \mathrm{kg} / \mathrm{day}$ donepezil. However, in a study in which pregnant rats were given up to $10 \mathrm{mg} / \mathrm{kg} / \mathrm{day}$ from day 17 of gestation through day 20 postpartum, there was a slight increase in still births and a slight decrease in pup survival through day 4 postpartum at this dose the next lower dose tested was $3 \mathrm{mg} / \mathrm{kg} / \mathrm{day}$. There are no adequate or well-controlled studies in pregnant women. ARICEPT should be used during pregnancy only if the potential benetit risk to the fetus. Nursing Mothers It is not known whether donepezil is excreted in human breast milk. ARICEPT has no indication for use in nursing mothers. Pediatric Use There are no adequate and well-controlied trials to document thas

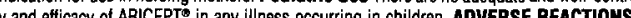

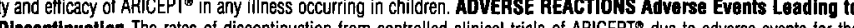
from controlled clinical trials of ARICEPT ${ }^{-}$due to adverse events for the ARICEPT $5 \mathrm{mg} /$ day treatment groups were comparable to those of placebo-treatment groups at approximately $5 \%$. The rate of discontinuation of patients who received 7-day escalations from $5 \mathrm{mg} / \mathrm{day}$ to $10 \mathrm{mg} /$ day, was higher at $13 \%$. The most common adverse events leading to discontinuation, detined as those occurring in at least $2 \%$ of patients and at twice the incidence seen in placebo patients, are shown in Table 1.

Table 1. Most Frequent Adverse Events Leading to Withdrawal Irom Controlied Cilnical Trials by Dose Group

\begin{tabular}{lccc}
\hline Dose Group & Placebo & $\mathbf{5 ~ m g / d a y ~ A R I C E P T ~}$ & $\mathbf{1 0}^{*} \mathbf{~ m g / d a y ~ A R I C E P T}$ \\
$\begin{array}{l}\text { Patients Randomized } \\
\text { Event\%olscontinuing }\end{array}$ & 355 & 350 & 315 \\
Nausea & $1 \%$ & $1 \%$ & $3 \%$ \\
Diarrhea & $0 \%$ & $<1 \%$ & $3 \%$ \\
Vomiting & $<1 \%$ & $<1 \%$ & $2 \%$
\end{tabular}

Most Frequent Adverse Clinical Events Seen In Assoclation with the Use of ARICEPT The most common adverse events, defined as those occurring at a frequency of at least $5 \%$ in patients receiving $10 \mathrm{mo} /$ day and twice the placebo rate, are largely predicted by ARICEPT's 's cholinomimetic effects. These include nausea, diarrhea, insomnia, vomiting bo rate, are largely predicted by ARICEPT's cholinomimetic effects. These include nausea, diarrhea, insomnia, vomiting, muscle cramp, fatigue and anorexia. These adverse events were often of mild intensity and transient, resolving during
continued ARICEPT' treatment without the need for dose modification. There is evidence to suggest that the frequency of continued ARICEPT treatment without the need for dose modification. There is evidence to suggest that the frequency of
these common adverse events may be affected by the rate of titration. An open-label study was conducted with 269 patients who received placebo in the 15 - and 30 -week studies. These patients were titrated to a dose of $10 \mathrm{mg} /$ day over a 6 -week period. The rates of common adverse events were lower than those seen in patients titrated to $10 \mathrm{mg} / \mathrm{day}$ over one week in the controlled clinical trials and were comparable to those seen in patients on $5 \mathrm{mg} /$ day. See Table 2 for a comparison of the most common adverse events following one and six week titration regimens.

Table 2. Comparison of Rates of Adverse Events in Patlents Titraled to $10 \mathrm{mg} /$ day Over 1 and 6 Weeks

\begin{tabular}{|c|c|c|c|c|}
\hline Adverse Event & $\begin{array}{l}\text { Placebo } \\
(n=315)\end{array}$ & $\begin{array}{c}\text { No titration } \\
5 \text { mg/day } \\
(n=311)\end{array}$ & $\begin{array}{c}\text { One-weok titration } \\
10 \mathrm{mg} / \mathrm{day} \\
(\mathrm{n}=315)\end{array}$ & $\begin{array}{c}\text { Six-week titration } \\
10 \mathrm{mg} / \mathrm{day} \\
(\mathrm{n}=269)\end{array}$ \\
\hline Nausea & $6 \%$ & $5 \%$ & $19 \%$ & $6 \%$ \\
\hline Diarrhea & $5 \%$ & $8 \%$ & $15 \%$ & $9 \%$ \\
\hline Insomnia & $6 \%$ & $6 \%$ & $14 \%$ & $6 \%$ \\
\hline Fatigue & $3 \%$ & $4 \%$ & $8 \%$ & $3 \%$ \\
\hline Vomiting & $3 \%$ & $3 \%$ & $8 \%$ & $5 \%$ \\
\hline Muscle cramps & $2 \%$ & $6 \%$ & $8 \%$ & $3 \%$ \\
\hline Anorexia & $2 \%$ & $3 \%$ & $7 \%$ & $3 \%$ \\
\hline
\end{tabular}

Adverse Events Reported in Controlled Trials The events cited reflect experience gained under closely monitored conditions of cilinical trials in a highly setected patient population. in actuaclinical pactice or in other clinical trials, these frequency estimates may not apply, as the conditions of use, reporting behavior, and the kinds of patients treated may differ. Tabie 3 lists treatment emeroent signs and symptoms that were reported in at least $2 \%$ of patients in placebo-controlled trials who received ARICEPT and for which the rate of occurrence was greater for ARICEPT assigned than placebo assigned patients. In general, adverse events occurred more frequently in temale patients and with advancing age.
Table 3. Adverse Events Reported In Controlied Clinical Trials

in at Least $2 \%$ of Patients Receiving ARICEPT (donepezll HCI) and at a Higher Frequency than Placebo-treated Pationts

\begin{tabular}{|c|c|c|}
\hline Body System/Adverse Event & $\begin{array}{l}\text { Placebo } \\
(n=355)\end{array}$ & $\begin{array}{r}\text { ARICEPT } \\
(n=747)\end{array}$ \\
\hline \multicolumn{3}{|l|}{ Body as a Whole } \\
\hline Headache & 9 & 10 \\
\hline Pain, various locations & 8 & 9 \\
\hline Accident & 6 & 7 \\
\hline Fatigue & 3 & 5 \\
\hline \multicolumn{3}{|l|}{ Cardlovascular System } \\
\hline Syncope & 1 & 2 \\
\hline \multicolumn{3}{|l|}{ Digestive System } \\
\hline Nausea & 6 & 11 \\
\hline Diarrhea & 5 & 10 \\
\hline Vomiting & 3 & 5 \\
\hline Anorexia & 2 & 4 \\
\hline \multicolumn{3}{|l|}{ Hemic and Lymphatic System } \\
\hline Ecchymosis & 3 & 4 \\
\hline \multicolumn{3}{|l|}{ Metabolic and Nutritional Systems } \\
\hline Weight Decrease & 1 & 3 \\
\hline \multicolumn{3}{|l|}{ Musculoskeletal System } \\
\hline Muscle Cramps & 2 & 6 \\
\hline Arthritis & 1 & 2 \\
\hline \multicolumn{3}{|l|}{ Nervous System } \\
\hline Insomnia & 6 & 9 \\
\hline Dizziness & 6 & 8 \\
\hline Depression & $<1$ & 3 \\
\hline Abnormal Dreams & 0 & 3 \\
\hline Somnolence & $<1$ & 2 \\
\hline Urogenital System & & \\
\hline
\end{tabular}

Other Adverse Events Observed During Clinical Trials ARICEPT ${ }^{\star}$ has been administered to over 1700 individuals dusing clinical trials worldwide. Approximately 1200 of these patients have been treated for al least 3 months and more than 1000 patients have been treated for at least 6 months. Controlled and uncontrolled trials in the United States included approximately 900 patients. In regards to the highest dose of $10 \mathrm{mg} /$ day, this population includes 650 patients treated for 3 months, 475 patients treated tor 6 months and 116 patients treated for over 1 year. The range of patient exposure is from 1

to 1214 days. Treatment emergent signs and symptoms that occurred during 3 controlled clinical trials and two open-label trials in the United States were recorded as
adverse events by the clinical investigators using terminology of their own choosing. To provide an overall estimate of the proportion of individuals having similar types of events, the events were grouped into a smaller number of standardized categories using a mod ffied COSTART dictionary and event trequencies were calculated across all studies. These categories are used in the listing below. The frequencies represent the proportion of 900 patients from these trials who experienced that event while receiving ARICEPT All adverse events occurring at least twice are included, except tor those already listed in Tables 2 or 3, COSTART terms too general to be informative, or events less likely to be orug caused. Events are classified by body systern and listed using the following definitions trequent adverse events - those occurring in at least 1/100 patients; infrequent adverse events - those occurring in 1/100 to $1 / 1000$ patients. These adverse events are not necessarily reiated to ARICEPT treatment and in most cases were observed at a similar frequency in placebo-treated patients in the controlled studies. No important additional adverse events were seen in studies conducted outside the United States. Body as a Whole: Frequent: influenza, chest pain, toothache; Infrequent: tever edema face, periorbital edema, hernia hiatal, abscess, cellulitis, chills, generalized coldness, head fullness, listlessness. Cardiovascular System: Frequent: hypertension, vasodilation, atrial fibrillation, hot flashes, hypotension; Infrequent: angina pectoris, postural hypotension, myocardial infarction. AV block (first degree), congestive heart failure, arteritis, bradycardia, peripheral vascular disease, supraventricular tachycardia, deep vein thrombosis. Digestive System: Frequent: fecal incontinence, gastrointestinal bleeding, bloating, epigastric pain; Infrequent: eructation, gingivitis, increased appetite, flatulence, periodontal abscess, cholelithiasis, diverticulitis, drooling, dry mouth, fever sore, gastritis, irritable colon tongue edema epigastric distress, gastroenteritis, increased transaminases, hemorihoids, ileus, increased thirst jaundice, melena, polyclipsia, duodenal ulcer, stomach ulcer. Endocrine system: Infrequent diabetes mellitus, goiter Hemic and Lymphatic System: Infrequent: anemia, thrombocythemia, thrombocytopenia, eosinophilia, enythrocytopenia. Metabolls and Nutrtional Dlsordors: Frequent: dehydration; Infrequent: gout, hypokalemia, increased creatine (tracture Infrequent: muscle weakness, muscle fasciculation. Nervous systam: Frequent: delusions, tremor, irritability, paresthesia, aggression, vertigo, ataxia, increased libido, restlessness, abnomal crying, nervousness, aphasia; Infrequent: cerebrovascular accident, intracranial hemorrhage, transient ischemic attack, emotional lability, neuralgia, coldness (localized) muscle spasm, dysphoria, gait abnormality, hypertonia, hypokinesia, neurodermatitis, numbness (localized), paranoia dysarthria, dysphasia hostility, decreased libido, melancholia, emotional withdrawal, nystagmus, pacing. Respiratory Sysiem: Frequent: dyspnea, sore throat, bronchitis; Infrequent: epistaxis, post nasal drip, pneumonia, hyperventilation pulmonary congestion, wheezing hypoxia, pharyngitis, pleurisy pulmonary collapse, sleep apnea, snoring Sidn and Appendages: Frequent pruritus, diaphoresis, unticaria; infrequent: dermatitis, erythema, skin discoloration hyperkeratosis, alopecia, fungal dermatitis, herpes zoster, hirsutism, skin striae, night sweats, skin ulcer. Special Senses: Frequent: cataract, eye irritation, vision blurred; infrequent: dry eyes, glaucoma, earache, tinnitus, blepharitis, decreased hearing, retinal hemorrhage, otitis externa, otitis media, bad taste, conjunctival hemorrhage, ear buzing, motion sickness, spots before eyes. Urogenital Syatem: Frequent: urinary incontinence, nocturia; Infrequent: dysuria, hematuria, urinary urgency, metrorrhagia, cystitis, enuresis, prostate hypertrophy, pyelonephritis, inability to empty bladder, breast fibroadenosis, fibrocystic breast, mastitis, pyuria, renal failure, vaginitis. Postintroduction Reports Voluntary reports of adverse events temporally associated with ARICEPT that have been received since market introduction that are not listed above, and that there is inadequate data to determine the causal relationship with the drug include the following: abdominal pain, agitation, cholecystitis, confusion, convulsions, hallucinations, heart block (all types), hemolytic anemia, hepatitis, hyponatremia pancreatitis, and rash. OVERDOSAGE Because strategles for the management of overdose are continually ovolving, it is advisable to contact a Poison Control Center to determine the latest recommendations for the management of an overdose of any drug. As in any case of overdose, general supportive measures should be utilized. Overdosage with cholinesterase inhibitors can result in cholinergic crisis characterized by severe nausea, vomiting salivation, sweating, bradycardia, hypotension, respiratory depression, collapse and convulsions. Increasing muscle weaknes is a possibility and may result in death if respiratory muscles are involved. Tertiary anticholinergics such as atropine may be used as an antidote for ARICEPT overdosage. Intravenous atropine sulfate titrated to effect is recommended: an initial dose of 1.0 to $2.0 \mathrm{mg} \mathrm{IV}$ with subsequent doses based upon clinical response. Alypical responses in blood pressure and heart rate have been reported with other cholinomimetics when co-administered with quaternary anticholinergics such as alycopyrrolate. It is not known whether ARICEPT and/or its metabolites can be removed by dialysis (hemodialysis, peritoneal dialysis, or hemofiltration). Dose-related signs of toxicity in animals included reduced spontaneous movement prone position, staggering gait, lacrimation, clonic convulsions, depressed respiration, salivation, miosis, tremors, fasciculation and lower body surface temperature. DOSAGE AND ADMINISTRATION The dosages of ARICEPT ${ }^{*}$ shown to be effective in controlled clinical trials are $5 \mathrm{mg}$ and $10 \mathrm{mg}$ administered once per day. Controlled clinical trials indicated that the $10 \mathrm{mg}$ dose, with a one week titration, is likely to be associated with a higher incidence of cholinergic adverse events than the 5 $\mathrm{mg}$ dose. Because steady state is not achieved for 15 days and because the incidence of such effects may be intluenced by the rate of dose escalation, treatment with a dose of $10 \mathrm{mg}$ should not be contemplated until patients have been on a daily dose of $5 \mathrm{mg}$ for 4106 weeks. Whether or not to employ a dose of $10 \mathrm{mg}$ is a matter of prescriber and patient preference ARICEPT should be taken in the evening, just prior to retiring, and may be taken with or without food.

Revised September 1999

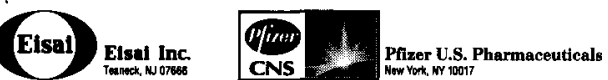

- 2000, Eisai Inc. and Pfizer Inc 


\section{CNS SPECTRUMS}

The International Journal of Neuropsychiatric Medicine

\section{EDITOR}

Jack M. Gorman, MD

College of Physicians and

Surgeons, Columbia University

New York, NY

\section{INTERNATIONAL EDITOR}

Joseph Zohar, MD

Chaim Sheba Medical Center

Tel Aviv, Israel

\section{ASSOCIATE INTERNATIONAL EDITORS} EUROPE

Donatella Marazziti, MD

University of Pisa

Pisa, Italy

\section{MID-ATLANTIC}

Dan J. Stein, MB

University of Stellenbosch

Tygerberg, South Africa

\section{FAR EAST}

Shigeto Yamawaki, MD, PhD

Hiroshima University School of

Medicine

Hiroshima, Japan

\section{EDITORIAL DIRECTOR}

James M. La Rossa Jr.

FOUNDING EDITOR

Eric Hollander, MD

\section{BOARD OF ADVISORS}

Margaret Altemus, MD

Cornell University Medical Center

New York, NY

Mitchell F. Brin, MD

Mount Sinai School of Medicine

New York, NY

Dennis S. Charney, MD

Yale University

New Haven, CT

Jeffrey L. Cummings, MD

University of California

Los Angeles, CA

Dwight L. Evans, MD

University of Pennsylvania

Philadelphia, PA

Mark George, MD

Medical University of South Carolina

Charleston, SC

Thomas R. Insel, MD

Yerkes Primate Labs

Emory University School of Medicine Atlanta, GA

Lorrin M. Koran, MD

Stanford University Medical School

Herbert Y. Meltzer, MD

Vanderbilt University Medical Center Nashville, TN

Stuart A. Montgomery, MD

St. Mary's Hospital Medical School London, United Kingdom

Dennis L. Murphy, MD

National Institute of Mental Health

Bethesda, MD
Stanford, CA

Charles B. Nemeroff, MD, PhD

Emory University School of Medicine Atlanta, GA

Humberto Nicolini, MD, PhD

Instituto Mexicano de Psiquiatria Mexico

Katharine Phillips, MD

Brown University

Providence, Rl

Harold A. Pincus, MD

University of Pittsburgh Pittsburgh, PA

Scott L. Rauch, MD

Massachusetts General Hospital

Charlestown, MA

Alan Schatzberg, MD

Stanford University Medical School

Stanford, CA

Norman Sussman, MD

New York University Medical School New York, NY

Neal R. Swerdlow, MD, PhD

University of California, San Diego

La Jolla, CA

Michael R. Trimble, MD

National Hospital for Neurology

and Neurosurgery

London, United Kingdom

Herman G.M. Westenberg, MD

University Hospital Utrecht

Utrecht, The Netherlands

Richard Wyatt, MD

National Institute of Mental Health

Bethesda, MD

Stuart Yudofsky, MD

Baylor College of Medicine

Houston, TX

\section{CORPORATION COUNSEL}

Kevin F. Saer, Esq.

Davis, Wright \& Tremaine

Christopher Naccari

José R. Ralat

Amanda Schoenberg

PRODUCTION COORDINATOR

Jesse D. Soll

PRODUCTION ASSISTANT

Mark Unterberger

ASSISTANT ART DIRECTOR

Benjamin Balcomb

COPY EDITORS

Ava Albrecht, MD

Clinton Corbett

Stephanie Kawada

Meg Phelan

ADMINISTRATIVE ASSISTANT

Claudette Crawford

CONTROLLER

David Windsor
PRESIDENT \& DIRECTOR

OF SALES

Darren L. Brodeur

DIRECTOR, ONCOLOGY SALES

Paul McDaniel

NATIONAL ACCOUNTS MANAGER-

EMERGING MARKETS

Dena M. Trakes

NATIONAL ACCOUNTS MANAGERBROADCAST MEDIA

Christopher Van Denburg

ASSOCIATE SALES MANAGER-

LATIN AMERICA

James Kassaris

PUBLISHER \& FOUNDER

James M. La Rossa Jr. 


\section{In the Journal of June 2001}

\section{APPLYING CIRCADIAN RHYTHMS TO MEDICAL PRACTICE \\ page 467}

"Improper BP control throughout the course of 24 hours can cause neurologic disorders. Twenty-four-hour BP control is the goal of antihypertensive therapy, and a large variety of different classes of medications are available to choose from to reach that goal. Most of these medicines are intended for morning ingestion, and most aim at maintaining near-constant plasma-drug concentration during the day and night. From a regulatory perspective, 24-hour $\mathrm{BP}$ control means that the magnitude of the BP-lowering effect at the end of the daily dosing interval (when the drug level is lowest) is $50 \%$ or more of the peak BP-lowering effect (when the drug level is highest). However, this seems to be an inadequate clinical definition because it fails to take into account all the relevant features of the circadian-BP rhythm as they relate to the risk of cardiovascular events and neurologic end-organ injury."

\section{SEASONAL DEPRESSION AND BIOLOGICAL RHYTHMS page 487}

"A close relationship between depression and biological rhythms has long been evident. Symptoms of depression are often circadian in nature: for example, a depressed mood is typically worse in the morning and improves during the day. Sleep during depression is usually disrupted. The most usual form is insomnia in the last hours of normal sleep, or early morning awakening. In sleep recordings, a reduced time of onset of rapid eye movement sleep (REM latency) is frequently found. Other patients may have insomnia in the initial and/or middle phases of sleep, while others may have insomnia in all three phases of sleep: initial, middle, and terminal. Depressed patients may show increased sleep (hypersomnia), falling asleep too early, or sleeping too late. Furthermore, a relationship between depression and seasonal rhythms has also been long noted. Episodes of depression are most likely to start in the spring or fall, with some patients having repeated recurrences of depression beginning in the spring or fall, but rarely both. Patients with winter SAD-a specific type of seasonal depression-experience recurrent episodes of depression beginning in the fall and ending in the spring."

\section{IRREGULAR MELATONIN LEVELS AND SLEEP DIFFICULTIES IN THE ELDERLY \\ page 502}

"Previous studies of age-related changes in melatonin production found reduced serum melatonin concentrations in old age. Delayed nocturnal melatonin onset and peak time have also been reported in old age. However, none of these studies distinguished between elderly people without sleep complaints and those suffering from sleep disorders. In recent years, our laboratory has been involved in a largescale project aimed at investigating the role of endogenous melatonin in sleep-wake regulation and the effects of pharmacologic levels of melatonin on sleep in the elderly."

\section{FLUVOXAMINE LINKED TO SLEEP DISORDERS?}

\section{page 511}

"Clinically, it is advised for doctors treating patients with psychotropic drugs, especially SSRIs and FVA, to take into consideration CRSD as a possible side effect. Often when psychotropic drugs are prescribed, a side effect of sleep difficulty is diagnosed under the general heading of insomnia. As we have shown, the new onset of a sleep problem may well be CRSD, which can be fairly easily diagnosed and confirmed, and often simply treated by changing the implicated drug prescribed or adding melatonin."

\section{HEAVY SMOKING AND SCHIZOPHRENIA page 514}

"The mentally ill smoke at a rate higher than the general population. Patients with chronic schizophrenia smoke at a rate approaching $90 \%$, while lifetime smoking rates for the general community are about $18 \%$. Glassman and colleagues suggested that chronic smoking is associated with a reduction in the firing of nigrostriatal dopaminergic neurons in the absence of changes in the numbers of dopamine receptors and in the dopamine transporter. The reduced dopamine turnover associated with the increased numbers of high-affinity nicotine receptors is consistent with the attenuated efficacy of these receptors in smokers. Many investigators have supported an early processing deficit in schizophrenia. There is a significant association between the missing peaks of the auditory brainstem responses and the Brief Psychiatric Rating Scale (BPRS) negative-symptom cluster or the total score of the scale of assessment of negative symptoms (SANS). This suggests that some patients with schizophrenia, especially those with negative symptoms, have an abnormality in the input processing of auditory information in the lower brainstem. Igata and colleagues, on the other hand, found that smoking affects brainstem auditory evoked potentials (BAEPs) through many mechanisms." 


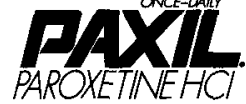

References: 1. Diagnostic and Statistical Manual of Mental Disorders: DSM-N-TRTM 4th ed. Washington, DC: Ameriçan Psychiatric Association; 2000. 2. Ballenger JC, Davidson JRT, Lecrubier $Y$, et al. Consensus statement on generalised anxiety disorder. In press. 3. Paxito (paroxetine HCl) Prescribing Information.

\section{PAXIL (brand of paroxetine hydrochloride}

See complete prescribing information in SmithKline Beecham Pharmaceuticals literature. The following is a brief sumnary.

INDICATIONS AND USAGE: Paxil is indicated for the treatment of depression, cbsessions and compulsions in patients with, obsessive compulsive disorder (OCD) as defined in DSM-IV panic disorder, with or without agora-
phobia, as defined in DSM-IV, social anxiety disorder, as defined in DSM-NV, and generalized anxiety disorder, as defined in DSM-N.

CONTRAINDICATIONS: Concomitant use in patients taking either monoamine oxidase inhibitors (MAOIs) o thioridazine is contraindicated. (See WARNINGS and PRECAUTIONS.) Contraindicated in patients with a hyperWARNINGS: Interactions with MAOls may occur. Given the fatal interactions reported with concomitant or immediately consecutive administration of MAOls and other SSRIs, do not use Paxil in combitant or immediately consecutive administration of MAOs and other SSRis, do not use Paxil in combi-
nation with a MAOI or within 2 weeks of discontinuing MAOI treatment. Allow at least 2 weeks after stopping Paxil before starting a MAOI.

\section{Potential Interaction with Thioridazine}

Thioridazine administration alone produces prolongation of the QTc interval, which is associated with Thioridazine administration alone produces prolongation of the QTc interval, which is associated with
serious ventricular arrhythmias, such as torsade de pointes-type arrhythmias, and sudden death. This effect appears to be dose rolated.

An in vivo study suggests that drugs which inhibit $P_{450} \| D_{6}$, such as paroxetine, will elevate plasma levels of thio
thioridazine.

PRECAUTIONS: As with all antidepressants, use Paxil cautiously in patients with a history of mania.

Use Paxil cautiousiy in patients with a history of seizures. Discontinue it in any patient who develops seizures. The possibility of suicide attempt is inherent in depression and may persist until significant remission occurs. Close supervision of high-risk patients should accompany initial drug therapy. Write Paxil prescriptions for the
smallest quantity of tablets consistent with good patient management in order to reduce the risk of overdose. Reversible hyponatremia has been reported, mainly in elderly patients, patients taking diuretics or those who were otherwise volume depleted. Abnormal bleeding (mostly ecchymosis and purpura), including a case of impaired
platelet aggregation, has been reported; the relationship to paroxetine is unclear.

Clinical experience with Paxil in patients with concomitant systemic illness is limited. Use cautiously in patients with diseases or conditions that could affect metabolism or hemodynamic responses. Observe the usual cautions in cardiac patients. In patients with severe renal impairment
impairment, a lower starting dose $(10 \mathrm{mg})$ should be used.

Caution patients about operating hazardous machinery. including automobiles, until they are reasonably sure that Paxil therapy does not affect their ability to engage in such activities. Tell patients 1) to continue therapy as directed; 2) to inform physicians about other medications they are taking or plan to take; 3 to avoid alcohol while tak-
ing Paxil; 4) to notify their physicians if they become pregnant or intend to become pregnant during therapy, or if heyre nursing.

Weakness, hyperreflexia, and incoordination following use of an SSRI and sumatriptan have been rarely reported Concomitant use of Paxil with tryptophan is not recommended. Use cautiously with warfarin. When administering Paxil with cimetidine, dosage adjustment of Paxil after the $20 \mathrm{mg}$ starting dose should be guided by clinical effect. When 50 -administering Paxil with phenobarbital or phenytoin, no initial Paxil dosage adjustment is needed; base
subsequent changes on clinical effect. Concomitant use of $P a x i l$ with drugs metabolized by cytochrome $P_{450} I_{6} D_{6}$ lantidepressants such as nortriptyline, amitriptyline, imipramine, desipramine and fluoxetine; phenothiazines; Type IC antiarthythmics such as propafenone, fecainide and encainide) or with drugs that inhibit this enzyme (e.g. quinidine) may require lower doses than usually prescribed for either Paxil or the other drug; approach concomiciated with elevated plasma levels of thioridazine, paroxetine and thioridazine should not be co-administered. An in vivo interaction study revealed that paroxetine had no effect on terfenadine pharmacokinetics. Additional in vitro studies showed that the inhibitory effects of paroxetine on other $\| A_{4}$ substrates lastemizole, cisapride, tria.
zolam and cyclosporin) was at least 100 times less potent than ketoconazole, a potent $\| I A_{4}$ inhibitor. Assuming that the relationship between paroxetine's in vitro Ki and its lack of effect on terfenadine's in vivo clearance predicts its effect on other III $A_{4}$ substrates, paroxetine's inhibition of IIIA $A_{4}$ activity should have little clinical significance. Use caution when co-administering Paxil with tricyclic antidepressants (ICAs). TCA plasma concentrations may need monitoring and the TCA dose may need to be reduced. Administration of Paxil with another tightly protein-bound drug may shift plasma concentrations, resulting in adverse effects from either drug. Concomitant use of
$P_{a x i l}$ and alcohol in depressed patients is not advised. Undertake concomitant use of $P_{a x i l}$ and lithium or digoxin cautiously. If adverse effects are seen when co-administering Paxil with procyclidine, reduce the procyclidine dose. Elevated theoph
ommended.

In 2-year studies, a significantly greater number of male rats in the $20 \mathrm{mg} / \mathrm{kg} /$ day group developed reticulum cell sarcomas vs. animals given doses of 1 or $5 \mathrm{mg} / \mathrm{kg} /$ day. There was also a significantly increased linear trend across dose groups for the occurrence of lymphoreticular tumors in male rats. Although there was a dose-related increase
in the number of tumors in mice, there was no drug-related increase in the number of mice with tumors. The clinin the number of tumors in mice, there was no drug-related increase in the number of mice with
ical significance of these findings is unknown. There is no evidence of mutagenicity with $P$ axil

fiats receiving paroxetine at $15 \mathrm{mg} / \mathrm{kg} /$ day $\left(2.4\right.$ times the MRHD on a $\mathrm{mg} / \mathrm{m}^{2}$ basis) showed a reduced pregnancy

Pregnancy Category C. Reproduction studies performed in rats and rabbits at doses up to $6 \mathrm{mg} / \mathrm{kg} / \mathrm{day}, 8.1$ (rat) and 1.9 (rabbit) times the MRHD on a $\mathrm{mg} / \mathrm{m}^{2}$ basis, have revealed no evidence of teratogenic effects or of selective toxicity to the fetus. However, rat pup deaths increased during the first 4 days of lactation when dosing occurred during the last trimester of gestation and continued throughout lactation. The cause of these deaths is not known. the potential benefit justifies the potential risk to the fetus. The effect of Paxil on labor and delivery in hurnans is unknown. Paroxetine is secreted in human milk; exercise caution when administering Paxil to a nursing woman. Safety and effectiveness in the pediatric population have not been established

In woridwide premarketing Paxil clinical trials, $17 \%$ of Paxi-treated patients were $\geq 65$ years of age. Pharmacokinetic studies revealed a decreased clearance in the elderly and a lower starting fose is recommended.

ADVERSE REACTIONS: Incidence in Controlled Trials-Commonly Observed Adverse Events in Controlled Clinical Trials: The most comminonly observed adverse events associated with the use of Paxil in the treatment of depression (incidence of $5 \%$ or greater and incidence for Paxil at least twice that for placebo): asthenia
$(15 \%$ vs. $6 \%)$, sweating $(11 \%$ vs. $2 \%)$, nausea $(26 \%$ vs. $9 \%)$, decreased appetite ( $6 \%$ vs. $2 \%)$ somnolence $(23 \%)$ (15\% vs. $6 \%)$, sweating $(11 \%$ vs. $2 \%)$, nausea $(26 \%$ vs. $9 \%)$, decreased appetite $(6 \%$ vs. $2 \%)$. somnolence $(23 \%)$
vs. $9 \%$, dizziness $(13 \%$ vs. $6 \%)$, insomnia $(13 \%$ vs. $6 \%)$, tremor $(8 \%$ vs. $2 \%)$, nervousness $(5 \%$ vs. $3 \%)$, ejaculatory disturbance $(13 \%$ vs. $0 \%$ ) and other male genital disorders (10\% vs. $0 \%)$. compulsive disorder (incidence of $5 \%$ or greater and incidence for Paxil at least twice that of placebo) were: nausea $(23 \%$ vs. $10 \%)$, dry mouth $(\{8 \%$ vs. $9 \%$ ), decreased appetite ( $(9 \%$ vs. $3 \%)$, constipation $(16 \%$ vs. $6 \%)$, dizziness
$(12 \%$ vs. $6 \%)$, somnolence $(24 \%$ vs. $7 \%)$, tremor $(11 \%$ vs. $1 \%)$, sweating $(9 \%$ vs. $3 \%)$, impotence $(8 \%$ vs. $1 \%)$ and abnormal ejaculation $(23 \%$ vs. $1 \%)$

The most commonly observed adverse events associated with the use of paroxetine in the treatment of panic disorder lincidence of $5 \%$ or greater and incidence for Paxil at least twice that for placebo) were: asthenia (14\%
vs. $5 \%$, sweating $(14 \%$ vs. $6 \%$, decreased appetite $(7 \%$ vs. $3 \%$ ), libido decreased ( $(9 \%$ vs. $1 \%$ ), tremor ( $9 \%$ vs. $1 \%$ ), abnormal ejaculation ( $21 \%$ vs. $1 \%$, female genital disorders ( $9 \%$ vs. $1 \%$ ) and impotence ( $5 \%$ vs. $0 \%$ ).
The most commonly observed adverse events associated with the use of paroxetine in the treatment of social anxiThe most commonly observed adverse events associated with the use of paroxetine in the treatmerit of sociai anxi-
ety disorder (incidence of $5 \%$ or greater and incidence for Paxil at least twice that for placebol were: sweating $\{9 \%$ vs. $2 \%)$, nausea $(25 \%$ vs. $7 \%$, dry mouth $(9 \%$ vs. $3 \%)$, constipation $(5 \%$ vs. $2 \%)$, decreased appetite $[8 \%$ vs.
$2 \%)$, somnolence $(22 \%$ vs. $5 \%$, tremor $(9 \%$ vs. $1 \%)$, libido decreased $(12 \%$ vs. $1 \%$ ) yawn $(5 \%$ vs. $1 \%)$, abnormal ejaculation $(28 \%$ vs $1 \%)$ female nenital disorders $(9 \%$ vs. $1 \%)$ and impotence $(5 \%$ vs. $1 \%)$

The most commonly observed adverse events associated with the use of paroxetine in the treatment of generalized anxiety disorder (incidence of $5 \%$ or greater and incidence for Paxil at least twice that for placebol were:
asthenia, infection, constipation, decreased appetite, dry mouth, nausea, libido decreased, somnolence, tremor,

asthenia, infection, constipation, dected
sweating, and abnormal ejaculation.

Twenty percent $\{1,199 / 6,145\}$ of Paxilpatients in worldwide clinical trials in depression and $16.1 \%$ (84/522), 11.8\% $\langle 64 / 542), 9.4 \%(44 / 469)$ and $10.7 \%$ (79/735) of Paxil patients in worldwide trials in social anxiety disorder, OCD. panic disorder and generalized anxiety disorder, respectively, discontinued treatment due to an adverse event. The most common events $(z 1 \%)$ associated with discontinuation and considered to be drug related include the
following: depression-somnolence, agitation, ejaculation, sweating; $\mathbf{O C D}$-insomnia, dizziness, constipation, nausea, asthenia, abnofmal ejaculation, impotence; panic disorder-somnolence, insomnia, nausea; social anxiety disorder-somnolence, insomnia, tremor, anxiety, dizziness, nausea, vomiting, flatulence, asthenia, abnormal ejaculation, sweating, libido decreased; gen-
eralized anxiety disorder-somnolence, dizziness, nausea, asthenia, abnormai ejaculation, sweating. (t) or more in patients dosed 120 to $50 \mathrm{mg} / \mathrm{day}$ for the treatment of depression headache at a frequency of $1 \%$ vasodilation: ynx disorder, dyspepsia; myopathy, myalgia, myasthenia; somnolence, dizziness, insomnia, tremor, nervousness, anxiety, paresthesia, libido decreased, drugged feeling, confusien; yawn; blurred vision, taste perversion; ejacula anxiety, paresthesla, libido decreased, drugged feeling, confusion; yawn; blurred vision, taste perversion; ejacula-
tory disturbance, other maie genital disorders, urinary frequency, urination disorder, female genital disorders. The following adverse events occurred at a frequency of $2 \%$ or more among $0 \mathrm{CD}$ patients on Paxil who participated in placebo-controlled trials of 12 weeks duration in which patients were dosed in a range of 20 to $60 \mathrm{mg} /$ ay or among patients with panic disorder on Paxil who participated in placebo-controlied trials of 10 to 12 week der on Paxi/ who participated in placebo-controlled trials of 12 weeks duration in which patients were dosed in a range of 20 to $50 \mathrm{mg} /$ day: asthenia, abdominal pain, chest pain, back pain, chills, trauma; vasodilation, palpitation; sweating, rash; nausea, dry mouth, constipation, diarrhea, decreased appetite, dyspepsia, flatulence, increased appetite, vomiting; myalgia; insomnia, somnolence, dizziness, tremor, nervousness, libido decreased, agitation, anxiety, abnormal dreams, concentration impaired, depersonalization, myoclonus, amnesia, rhinitis, pharyngitis, yawn; abnormal vision, taste perversion; abnormal ejaculation, dysmenorrhea, female genital disorder, impotence, urinary frequency, urination impaired, urimary tract infection.

The following adverse events occurred at a frequency of $2 \%$ or more among GAO patients on Paxil who participated in placebo-controlled trials of 8 weeks duration in which patients were dosed in a range of $10 \mathrm{mg} / \mathrm{day}$ to 50 $\mathrm{mg} / \mathrm{day}$; asthenia, headache, infection, vasodilation, sweating, nausea, dry mouth, constipation, diarrhea, decreased appetite vomiting, insomnia somnolence dizziness, tremor, nervousness, libido decreased, respiratory disorder, sinusitis, yawn, abnormal vision, abnormal ejaculation, fermale genital disorder impotence.

Studies in depression show a clear dose dependency for some of the more common adverse events associated with Paxil use. There was evidence of adaptation to some adverse events with continued Paxil therapy (e.g., nause

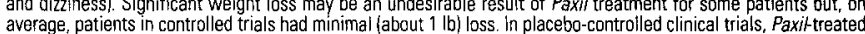
patients exhibited abnormal values on liver function tests no more frequentiy than placebo-treated patients.

in placebo-controlled clinical trials involving more than 2,500 patients with depression, 0CD, panic disorder, socia anxiety disorder or generalized anxiety disorder, the following incidences of untoward sexual experiences for patients receiving Paxil were reported, varying with the disease state: In males: decreased libido $(6 \%$ to $15 \%)$, ejaculatory disturbance, mostly delayed ejaculation $(13 \%$ to $28 \%)$, impotence $(2 \%$ to $8 \%)$. In females: decreased libido $(0 \%$ to $9 \%)$, orgasmic disturbance $(2 \%$ to $9 \%)$. The repo
$<5 \%$ among male and female patients receiving placebo

Other Events Observed During the Premarketing Evaluation of Paxil: During premarketing assessment in depression multiple doses of $P$ axil were administered to 6,145 patients in phase 2 and 3 studies. During premarand 735 patients, respectively, received multiple doses of Paxil The following adverse events were reported. Not "frequent" $=$ events occurring in at least $1 / 100$ patients; "infrequent" $=1 / 100$ to $1 / 1000$ patients; "rare" = less than 1/1000 patients. Events are classified within body system categories and entumerated in order of decreasing frequency using the above definitions. It is important

Body as a Whole; frequent: chills, malaise; infrequent: allergic reaction, face edema, moniliasis, neck pain; rare adrenergic syndrome, cellulitis, neck rigidity, pelvic pain, peritonitis, ulcer. Cardiovascular System: frequent hypertension, tachycardia; infrequent: bradycardia, hematoma, hypotension, migraine, syncope; rare: angina pectoris, arrhythmia nodal, atrial fibrillation, bundle branch block, cerebral ischemia, cerebrovascular accident, congestive heart failure, heart block, low cardiac output, myocardial infarct, myocardial ischemia, pallor, phlebitis, pulmonary embolus, supraventricular extrasystoles, thrombophlebitis, thrombosis, varicose vein, vascular headache, enteritis, gingivitis, glossitis, increased salivation, liver function tests abnormal, rectal hemorrhage, uicerative stomatitis, rare: aphthous stomatitis, bloody diarrhea, bulimia, cholelithiasis, duodenitis, enteritis, esophagitis, ecal impactions, fecal incontinence, gum hemorrhage, hematemesis, hepatitis, ileus, intestinal obstruction, jaundice, melena, mouth ulceration, peptic ulcer, salivary gland enlargement, stomach ulcer, stomatitis, tongue disthyroidism, thyroiditis. Hemic and Lymphatic Systems: infrequent: anemia, eosinophilia, leukocytosis, leukope nia, lymphadenopathy, purpura; rare: abnormal erythrocytes, basophilia, bleeding time increased, hypochromic anemia, iron deficiency anemia, lymphedema, abnormal lymphocytes, lymphocytosis, microcytic anemia, monocytosis, normocytic anemia. thrombocythemia, thrombocytopenia. Metabolic and Nutritional: frequent: weight gain. weight foss: infrequent: alkaline phosphatase increased, edema, peripheral edema, SGOr increased, SGP globulins thirs, rare. bilirubinemia, BUN increased, creatinine phosphokinase increased, dehydration, gamma hypocalcemia, hypoglycemia, hypokalemia, hyponatremia, ketosis, lactic dehydrogenase increased, non-protein nitrogen (NPN) increased; Musculoskeletal System: frequent: arthralgia; infrequent: arthritis, arthrosis; rare bursitis, myositis, osteoporosis, generalized spasm, tenosynovitis, tetany. Nervous System: frequent: emotional lability, vertigo; infrequent: abnormal thinking, alcohol abuse, ataxia, delirium, dystonia, dyskinesia, euphoria, hallucinations, hostility, hypertonia, hypesthesia, hypokinesia, incoordination, lack of emotion, libido increased, manic sia, choreoarthetosis, circumoral paresthesias, psychosis; rare: abnormal gait, akinesia, antisocial reaction, aphapyramida! syndrome, fasciculations, grand mal convulsion byperalgesia, hug dependence, dysarthria, extrameningitis, myelitis, neuralgia, neuropathy, nystagmus, peripheral neuritis, psychotic depression, reflexes decreased reflexes increased, stupor, torticollis, trismus, withdrawal syndrome. Respiratory System: infrequent: asthma, bronchitis, dyspnea, epistaxis, hyperventilation, pneumonia, respiratory flu, rare: emphysema, hemoptysis, hiccups, lung fibrosis, pulmonary edema, sputum increased, voice alteration. Skin and Appendages: frequent pruritus; infrequent: acre, alopecia, contact dermatitis, dry skin, ecchymosis, eczema, furunculosis, herpes simplex. maculopapular rash, photosensitivity, urticaria; rare: angioedema, erythema nodosum, enythema multiforme, exfoliative dermatitis, fungal dermatitis, herpes zoster, hirsutism, seborrhea, skin discoloration, skin hypertrophy, skin ulcer. Sweating decreased, vesiculobullous rash. Special Senses: frequent: tinnitus; infrequent: abnormality of accommodation, conjunctivitis, ear pain, eve pain, mydriasis, otitis media, photophobia; rare: amblyopia, anisocoria, blepharitis, cataract, conjunctival edema, corneal ulcer, deafness, exophthalmos, eye hemorrhage, glaucoma. hyperacusis, keratoconjunctivitis, night blindness, otitis externa, parosmia, ptosis, retinal hemorrhage, taste loss,
visual field defect. Urogenital System: infrequent: abortion, amenorrhea, breast pain, cystitis, dysuria, hematuria, menorrhagia, nocturia, poivuria, urinary incontinence, urinary retention, urinary urgency, vaginal moniliasis, vaginitis; rare: breast atrophy, breast enlargement, endometrial disorder, epididymitis, female lactation, fibrocys tic breast, kidney calculus, kidney pain, leukorrhea, mastitis, metrorhagia, nephritis, oliguria, pyuria, urethritis, uterine spasm, urolith, va

Voluntary reports of adverse events that have been received since market introduction and not listed above tha may have no causal relationship with Paxil include-acute pancreatitis, elevated liver function tests (the most severe cases were deaths due to liver necrosis, and grossly elevated transaminases associated with severe liver tion, symph), Guillain-Barre syndrome, toxic epidermal necrolysis, priapism, syndrome of inappropriate ADH secrepyramidal symptomsestive of prolactinemia and galactorrhea, neuroleptic malignant syndrome-like events; extraic crisis (which has which have included akathisia, bradykinesia, cogwheel rigidity, dystonia, hypertonia, oculogyassociated in some cases with concomitant use of serotonergic drugs, and with drugs which may have impaired Paxilmetabolism (symptoms have included agitation, confusion, diaphoresis, hallucinations, hyperreflexia, myoclonus, shivering, tachycardia and tremor), status epilepticus, acute renal failure, pulmonary hypertension, allergic alveolitis, anaphylaxis, eclampsia, laryngismus, optic neuritis, porphyria, ventricular fibrillation, ventricular tachy. cardia (including torsade de pointes), thrombocytopenia, hemolytic anemia, and events related to impaired hematoppiesis lincluding aplastic anemia, pancytopenia, bone marrow aplasia, and agranulocytosis). There have been spontaneous reports that discontinuation (particularty when abrupt) may lead to symptoms such as dizziness, sensory disturbances, agitation or anxiety, nausea and sweating; these events are generally self-limiting. There has been a report of an elevated phenytoin level after 4 weeks of Paxil and phenyton
of severe hypotension when Paxil was added to chronic metoprolol treatment.

DRUG ABUSE AND DEPENDENCE: Controlied Substance Class: Paxil is not a controlled substance. Evaluate patients carefully for history of drug abuse and observe such patients closely for signs of Paxil misuse or abuse e.g., development of tolerance, incrementations of dose, drug-seeking behaviorl.

BRS-PX:L20

(C)2001 The GlaxoSmithKline Group of Companies
All rights reserved. Printed in USA. PX7463 April 2001 


\section{NEW: 1ST AND ONLY}

SSRI FDA-APPROVED

\section{FOR GAD}

\section{Overpowered by \\ 1.A $A N I E T Y$}
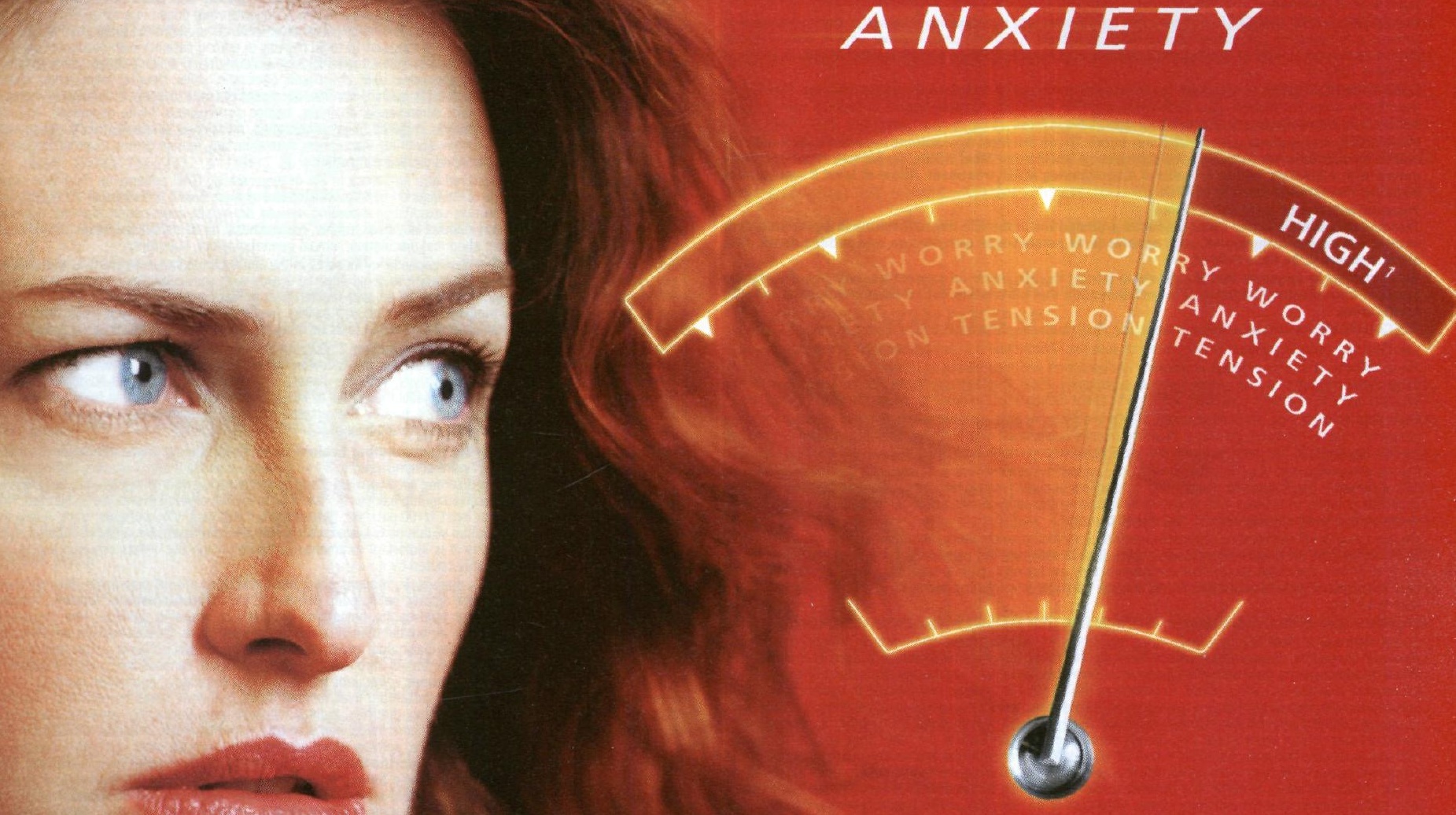

Empowered by Paxil

Generalized anxiety disorder (GAD) patients may suffer for up to $\mathbf{1 0}$ years before diagnosis and treatment, ${ }^{2}$ often believing their anxiousness is a part of their personality. With Paxil, the

Most common adverse events (incidence of $5 \%$ or greater and incidence for Paxil at least twice that for placebo) in depression, $O C D$, panic disorder, social anxiety disorder or GAD studies include asthenia, infection, sweating, nausea, dry mouth, constipation, decreased appetite, somnolence, dizziness, insomnia, libido decreased, tremor, nervousness, yawn, abnormal ejaculation, female genital disorders and impotence. Concomitant use of Paxil in patients taking monoamine oxidase inhibitors (MAOIs) or thioridazine is contraindicated.

\section{VISIT www.paxil.com}

Please see brief summary of prescribing information on adjacent page first and only SSRI FDA-approved for generalized anxiety, ${ }^{3}$ they can now find help....and hope.

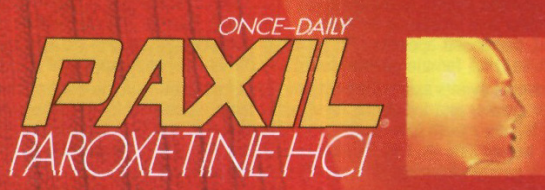

The anxiolytic antidepressant 


\section{Table of Contents}

Feature Articles

462 Introduction-Medical Chronobiology in Psychiatry and Neurology

By Yaron Dagan, MD, DSC

467 Circadian Rhythms in Medicine

By Michael H. Smolensky, PhD

487 Is Seasonal Affective Disorder a Disorder of Circadian Rhythms?

By Paul H. Desan, MD, PhD, and Dan A. Oren, MD

502 Melatonin Rhythm Abnormalities and Sleep Disorders in the Elderly

By Iris Haimov, PhD

\section{ORIGINAL RESEARCH}

511 Circadian Rhythm Sleep Disorders as a Possible Side Effect of Fluvoxamine

By Haggai Hermesh, MD, Hadas Lemberg, MSc, Judith Abadi, and Yaron Dagan, MD, DSC

\section{ORIGINAL RESEARCH}

514 The Effect of Smoking on Brainstem Auditory Evoked Potentials in Positive- and Negative-Symptom Schizophrenia By Ahmed Mubarak, MB, BCh, MSc, MD, and Adel Badawy, MB, BCh, MSc

\section{CNS SPECTRUMS}

The International Journal of Neuropsychiatric Medicine

$$
6
$$

Medical Chronobiology in Psychiatry and Neurology

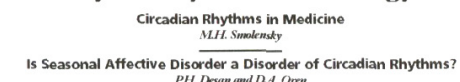

P.H. Drsan and DA. Orea

Melatonin Rhythm Abnormalities andSleep Disorders in the Elderly 1. Hainov

Circadian Rhythm Sleep Disorders as a Possible Side Eftect of Fluvoxamine

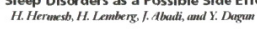

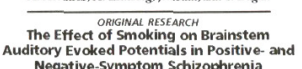

Auditory Evoked Potentials in Positive- and Negative-Symptom Schizophi

$$
\text { PRST PERSCO }
$$

The Rage to Know, the Rage to Teach, and the Rage to Heal: What is the Proper Bal
C.B. Nemeroff THE NEUPOLOGY OF BMavion Towards a Neurology of Aesthetics
M. Trimble
CNS SPECTRUMS

The International Journal of

Neuropsychiatric Medicine

Volume 6 - Number 6 June 2001

CNS Spectrums is a peer review journal and is indexed in EMBASE/Excerpta Medica, DIALOG, SilverPlatter, OVID, and Lexis-Nexis. CNS Spectrums is endorsed by, and is the official journal of, the International Neuropsychiatric Ass., with members in 30 countries.

\section{CNS Spectrums}

(ISSN 1092-8529)

is published monthly by

MedWorks Media,

333 Hudson Street, 7th Floor

New York, NY 10013.

Periodicals postage paid at New York, NY, and at additional mailing offices.

One year subscription rates:

domestic \$90;

foreign $\$ 145$;

in-training $\$ 50$.

For subscriptions:

Fax: 212-328-0600.

E-mail:

jrr@medworksmedia.com

Postmaster:

Send address changes to

CNS Spectrums

clo PPS Medical Marketing Group

264 Passaic Ave.

Fairview, NJ 07004-2595 


\section{$\overline{\text { CNS SPECTRUMS }}$}

The International Journal of

Neuropsychiatric Medicine

Volume 6 - Number 6 June 2001

\section{Table of Contents}

Departments/Monthly Columns

POINT \& COMMENTARY

457 Timing and the Rhythm of the Mind

By Joseph Zohar, MD

\section{THE NEUROLOGY OF BEHAVIOR}

458 Towards a Neurology of Aesthetics

By Michael Trimble, MD, FRCP, FRPsych

\section{FIRST PERSON}

459 The Rage to Know, the Rage to Teach, and the Rage to Heal: What Is the Proper Balance?

By Charles B. Nemeroff, MD, PhD

\section{CNS NEWS}

460 Briefs From the Fields of Neurology \& Neuropsychiatry

\section{CONTINUING MEDICAL EDUCATION GradWORKS}

527 This Continuing Medical Education series gives the reader the opportunity to test his/her understanding and recall of clinical material presented in this issue. Approved for 3.0 credit hours in Category 1

INDICES

Audit Bureau of Circulations

530 By subject and author

\section{MellworkedMedia}

\section{CNS Spectrums}

CNS Reviews ${ }^{\mathrm{T}}$

TEN-The Economics of Neuroscience ${ }^{\circledast}$

Psychopharmacology Bulletin ${ }^{\mathrm{TM}}$

Primary Psychiatry

Psiquiatría y Salud Integra/ ${ }^{\mathrm{TM}}$

Mental Fitness ${ }^{\circledast}$

Oncology Spectrums ${ }^{\mathrm{TM}}$

For editorial and advertising inquiries, please fax 212-328-0600.

Opinions and views expressed by authors are their own and do not necessarily reflect the views of the publisher, MedWorks Media, or the editorial advisory board. Advertisements in CNS Spectrums are accepted on the basis of adherence to ethical medical standards, but acceptance does not imply endorsement by CNS Spectrums, or the publisher.

CNS Spectrums ${ }^{\circledR}$ is a registered trademark of CNS Spectrums, LLC, New York, NY. CNS News ${ }^{\mathrm{TM}}$ is a trademark of MBL Communications, Inc., New York, NY.

Permission to reproduce articles in whole or part must be obtained in writing from the publisher.

Copyright $@ 2001$ by MedWorks Media. All rights reserved. Printed in the United States. 


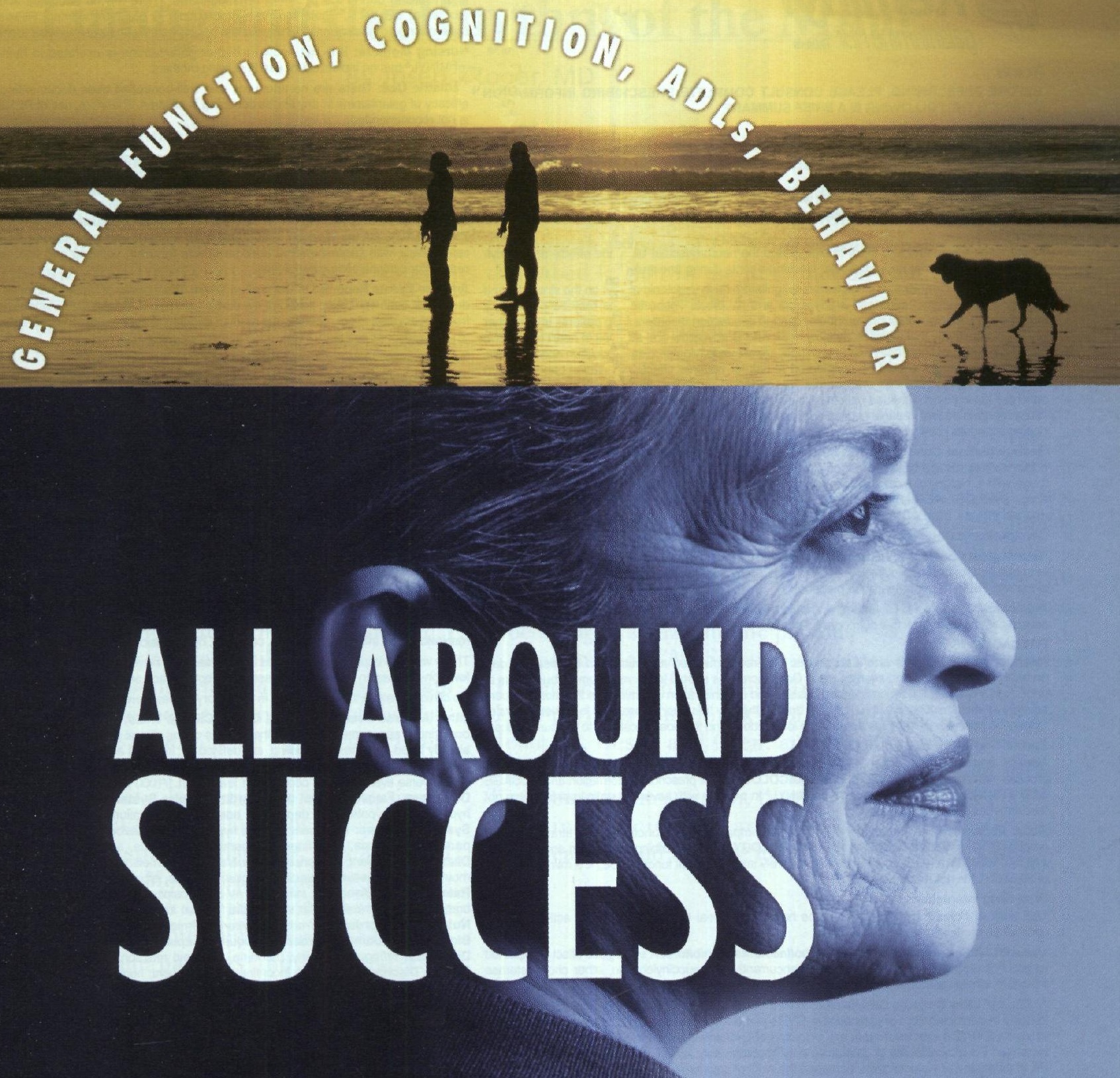

Now all the benefits of REMINYL can help patients with mild to moderate Alzheimer's disease (AD).'.

The most frequent adverse events that occurred with REMINYL were nausea, vomiting, diarrhea, anorexia, and weight loss.

Available in 4-mg, 8-mg, and 12-mg tablets.

www.reminyl.com

Please see brief summary of prescribing information on adjacent page.

References: 1. Tariot PN et al, Neurology. 2000;54:2269-2276. 2. Raskind MA et al. Neurology. 2000;54:2261-2268. 3. Wilcock GK et al. BMJ. 2000;321:1-7. 4. Data on file, Janssen.

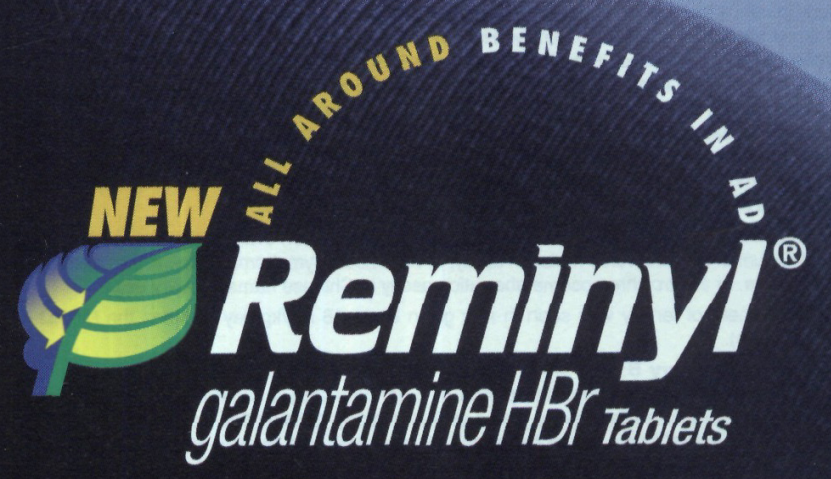


Reminyl'

galantamine HBr tablets

Ax only

BEFore PRESCRIBING, PLEASE CONSULT COMPLETE PRESCRIBING INFORMATION OF WHICH THE FOLLOWING IS A BRIEF SUMMARY.

INDICATION

REMINYL (galantamine hydrobromide) is indicated for the treatment of mild to moderate dementia of the Alzheimer's type.

CONTRAINDICATIONS

REMINYL is contraindicated in patients with known hypersensitivity to galantamine hydrobromide or to any excipients used in the formulation.

WARNINGS

Anesthesla: Galantamine is likely to exaggerate the neuromuscular blockade effects of succinylcholine-type and similar neuromuscular blocking agents during anesthesia.

Cardlovascular Condlitions: Cholinesterase inhibitors have vagotonic effects on the sinoatrial and atrioventricular nodes, leading to bradycardia and AV block. These actions may be particularly important to patients with supraventricular cardiac conduction disorders or to patients taking other drugs concomitantly that significantly slow heart rate. Bradycardia and all types of heart block have been reported in patients both with and without known underlying cardiac conduction abnormalities. Therefore all patients should be considered at risk for adverse effects on cardiac conduction. In randomized controlled trials, bradycardia was reported more frequently in galantamine-treated patients than in placebo-treated patients. No increased incidence of heart block was observed at the recommended doses. Patients treated with galantamine up to $24 \mathrm{mg} /$ day using the recommended dosing schedule showed a dose-related increase in risk of syncope.

Gastrointestinal Conditions: Patients should be monitored closely for symptoms of active or occult gastrointestinal bleeding, especially those with an increased risk for developing ulcers, e.g., those with a history of ulcer disease or patients using concurrent nonsteroidal anti-inflammatory drugs (NSAIDS). REMINYL has been shown to produce nausea, vomiting, diarrhea, anorexia and weight loss. (See ADVERSE REACTIONS)

Genitourinary: Cholinomimetics may cause bladder outfiow obstruction

Neurological Conditions: Seizures: Cholinesterase inhibitors are believed to have some potentia to cause generalized convulsions. In clinical trials, there was no increase in the incidence of convulsions with REMINYL ${ }^{\circ}$ compared to placebo.

Pulmonary Conditions: Galantamine should be prescribed with care to patients with a history of severe asthma or obstructive pulmonary disease.

PRECAUTIONS

Information for Patlents and Caregivers: The recommended administration is twice per day preferably with morning and evening meal. Dose increases should follow minimum of four weeks a prior dose. Following the recommended dosage and administration can minimize the most frequent adverse events associated with use of the drug. If therapy has been interrupted for several days or longer, the patient should be restarted at the lowest dose and the dose escalated to the current cose. Special Populations

Hepatic Impairment: In patients with moderately impaired hepatic function, dose titration should proceed cautiously (See CLINICAL PHARMACOLOGY in full prescribing information and DOSAGE AND ADMINISTRATION). The use of REMINYL in patients with severe hepatic impairment is not recommended.

Renal impairment: In patients with moderately impaired renal function, dose titration should proceed cautiously (See CUNICAL PHARMACOLOGY in full prescribing information and DOSAGE AND ADMINISTRATION). In patients with severely impaired renal function $\left(C L_{c r}<9 \mathrm{ml} / \mathrm{min}\right.$ ) the use of REMINYL is not recommended.

\section{Drug-Drug Interactions}

Use with Anticholinergics: Galantamine has the potential to interfere with the activity of anticholinergic medications.

Use with Chollnomimetics and Other Chollnesterase Inhibitors: A synergistic effect is expected when cholinesterase inhibitors are given concurrently with succinylcholine, other cholinesterase inhibitors, similar neuromuscular blocking agents or cholinergic agonists such as bethanechol.

A) Effect of Other Drugs on Galantamine: In vitro - CYP3A4 and CYP2D6 were the major enzymes involved in the metabolism of galantamine. CYP3A4 mediated the formation of galantamine- $\mathrm{N}$-oxide, whereas CYP2D6 was involved in the formation of O-desmethyl-galantamine. In vivo - Cimetidine increased the bioavailability of galantamine by approximately $16 \%$. Ranitidine had no effect on the PK of galantamine. Kotoconazole increased the AUC of galantamine by $30 \%$. Erythromycin affected the AUC of galantamine minimally ( $10 \%$ increase). Paroxetine increased the oral bioavailability of galantamine by about $40 \%$.

B) Effect of Galantamine on Other Drugs: In vitro Galantamine did not inhibit the metabolic pathways catalyzed by CYP1A2, CYP2A6, CYP3A4, CYP4A, CYP2C, CYP2D6 or CYP2E1. In vivo - The protein binding of wartarin was unaffected by galantamine. Galantamine at $24 \mathrm{mg} /$ day had no effect on the steady-state pharmacokinetics of digoxin ( 0.375 once daily) when they were coadministered. In this study, however, one healthy subject was hospitalized for $2^{\text {nd }}$ and $3^{\text {nd }}$ degree heart block and bradycardia.

Carcinogenesis, Mutagenesis and tmpairment of Fertlity: In a 24-month oral carcinogenicity study in rats, a trend for an increase in endometrial adenocarcinomas was observed at $10 \mathrm{mg} / \mathrm{kg} / \mathrm{day}$ (4 times the Maximum Recommended Human Dose [MRHD] on a $\mathrm{mg} / \mathrm{m}^{2}$ basis or 6 times on an exposure [AUC] basis and $30 \mathrm{mg} / \mathrm{kg} /$ day ( 12 times MRHD on a $\mathrm{mg} / \mathrm{m}^{2}$ basis or 19 times on an AUC basis). No increase in neoplastic changes was observed in females at $2.5 \mathrm{mg} / \mathrm{kg} /$ day (equivalent to the MPHD on a $\mathrm{mg} / \mathrm{m}^{2}$ basis or 2 times on an AUC basis) or in males up to the highest dose tested of $30 \mathrm{mg} / \mathrm{kg} /$ day (12 times the MRHD on a $\mathrm{mg} / \mathrm{m}^{2}$ and AUC basis). Galantamine was not carcinogenic in a 6-month oral carcinogenicity study in transgenic (P 53-deficient) mice up to $20 \mathrm{mg} / \mathrm{kg} / \mathrm{day}$ or in a 24-month oral carcinogenicity study in male and female mice up to $10 \mathrm{mg} / \mathrm{kg}$ /day (2 times the MRHD on a $\mathrm{mg} / \mathrm{m}^{2}$ basis and equivalent on an AUC basis)

Gaiantamine produced no evidence of genotoxic potential when evaluated in the in vitro Ames S. typhimurium or $E$. coli reverse mutation assay, in vitro mouse lymphoma assay, in vivo micronucleus test in mice, or in vitro chromosome aberration assay in Chinese hamster ovary cells.

No impairment of fertility was seen in rats given up to $16 \mathrm{mg} / \mathrm{kg} /$ day $(7$ times the MRHD on a $\mathrm{mg} / \mathrm{m}^{2}$ basis).

Pregnancy Category B: In a study in which rats were dosed from day 14 (females) or day 60 (males) prior to mating through the period of organogenesis, a slightly increased incidence of skeletal variations was observed at doses of $8 \mathrm{mg} / \mathrm{kg} /$ day ( 3 times the Maximum Recommended Human Dose (MRHD] on a $\mathrm{mg} / \mathrm{m}^{2}$ basis) and $16 \mathrm{mg} / \mathrm{kg} /$ day. in a study in which pregnant rats were dosed trom the beginning of organogenesis through day 21 post-partum, pup weights were decreased at 8 and $16 \mathrm{mg} / \mathrm{kg} / \mathrm{day}$, but no adverse effects on other postnatal developmenta parameters were seen. The doses causing the above effects in rats produced slight materna toxicity. No major malformations were caused in rats given up to $16 \mathrm{mg} / \mathrm{kg} / \mathrm{day}$. No drug related atogenic effects were observed in rabbits given up to $40 \mathrm{mg} / \mathrm{kg}$ /day (32 times the MRHD on a basis) during the period of organogenesis. There are no adequate and well-controlled studies of REMINYL (galantamine hydrobromide) in pregnant women. REMINYL ${ }^{*}$ should be used during pregnancy only if the potential benefit justifies the potential risk to the fetus.

Nursing Mothers: It is not known whether galantamine is excreted in human breast milk REMINYL has no indication for use in nursing mothers.

Pediatric Use: There are no adequate and well-controlled trials documenting the safety and efficacy of galantamine in any iliness occurring in children. Therefore, use of REMINYL ${ }^{\star}$ in children is not recommended.

ADVERSE REACTIONS

Adverse Events Leading to Discontinuation: In two large scale, placebo-controlled trials of 6 months duration, in which patients were titrated weekly from 8 to 16 to 24 , and to $32 \mathrm{mg} /$ day, the risk of discontinuation because of an adverse event in the galantamine group exceeded that in the placebo group by about threefold. In contrast, in a 5-month trial with escalation of the dose by $8 \mathrm{mg} /$ day every 4 weeks, the overall risk of discontinuation because of an adverse event was $7 \%$ $7 \%$, and $10 \%$ for the placebo, galantamine $16 \mathrm{mg} / \mathrm{day}_{\text {, }}$ and galantamine $24 \mathrm{mg} / \mathrm{day}$ groups respectively, with gastrointestinal adverse effects (nausea, vomiting and anorexia) the principle reason for discontinuing galantamine.

Adverse Events Reported in Controlled Trials: The majority of reported adverse events occurred during the dose-escalation period of the controlled trials. In those patients who experience the most frequent adverse event, nausea, the median duration of the nausea was 5 to 7 days.

Administration of REMINYL ${ }^{\infty}$ with food, the use of anti-emetic medication, and ensuring adequate fuid intake may reduce the impact of these events.

The most frequent adverse events, those occurring at a frequency of at least $5 \%$ and at leas twice the rate on placebo with the recommended maintenance dose of either $16 \mathrm{or} 24 \mathrm{mg} /$ day of REMINYL under conditions of every 4 week dose-escalation, were primarily gastrointestinal and tended to be less frequent with the $16 \mathrm{mg} /$ day recommended initial maintenance dose. They included nausea $(5 \%, 13 \%$ and $17 \%)$, vomiting $(1 \%, 6 \%$ and $10 \%)$, diarrhea $(6 \%, 12 \%$ and $6 \%)$ anorexia $(3 \%, 7 \%$ and $9 \%)$ and weight decrease $(1 \%, 5 \%$ and $5 \%)$ tor placebo, $16-\mathrm{mg} /$ day and 24-mg/day treatment groups respectively.

The most common adverse events (adverse events occurring with an incidence of $2 \%$ with REMINYL treatment and in which the incidence was greater than with placebo treatment) for patients in controlled trials who were treated with 16 or $24 \mathrm{mg} /$ day of REMINYL ${ }^{\circ}$ were: fatigue $5 \%$, syncope $2 \%$, dizziness $9 \%$, headache $8 \%$, tremor $3 \%$, nausea $24 \%$, vomiting $13 \%$, diarrhea $9 \%$, abdominal pain $5 \%$, dyspepsia $5 \%$, bradycardia $2 \%$, weight decrease $7 \%$, anorexia $9 \%$, depression $7 \%$, insomnia $5 \%$, somnolence $4 \%$, anemia $3 \%$, rhinitis $4 \%$, urinary tract infection $8 \%$ and hematuria $3 \%$.

Adverse events occurring with an incidence of at least $2 \%$ in placebo-treated patients that was either equal to or greater than with REMINYL ${ }^{\star}$ treatment were constipation, agitation, confusion, anxiety, hallucination, injury, back pain, peripheral edema, asthenia, chest pain, urinary incontinence, upper respiratory tract infection, bronchitis, coughing, hypertension, fall, and purpura.

There were no important differences in adverse event rates related to dose or sex. There were too few non-Caucasian patients to assess the effects of race on adverse event rates.

No clinically relevant abnormalities in laboratory values were observed.

Other Adverse Events Observed During Clinical Trials: The incidence of all adverse events occurring in approximately $0.1 \%$ of the patients during clinical trials, except for those adverse events already listed elsewhere in labeling, are defined as: frequent adverse events - those occurring in at east 1/100 patients; infrequent adverse events - those occurring in 1/100 to 1/1000 patients; and rare adverse events - those occurring in fewer than $1 / 1000$ patients. Body As a Whole - Genera Disorders: Frequent: chest pain Cardiovascular System Disorders: Intrequent: postural hypotension, hypotension, dependent edema, cardiac failure; Central \& Peripheral Nervous System Disorders: Infrequent: vertigo, hypertonia, convulsions, involuntary muscle contractions, paresthesia, ataxia, hypokinesia, hyperkinesia, apraxia, aphasia; Gastrolntestinal System Disorders: Frequent: flatulence; Infrequent: gastritis, melena, dysphagia, rectal hemorrhage, dry mouth, saliva increased, diverticulitis, gastroenteritis, hiccup; rare: esophageal pertoration; Heart Rate \& Rhythm Disorders: Infrequent:AV block, palpitation, atrial fibrillation, QT prolonged, buind branch block, supraventricular tachycardia, T wave inversion, ventricular tachycardia; Metabolic \& Nutritional Disorders: Infrequent: hyperglycemia, alkaline phosphatase increased; Platelet Bleeding \& Clotting Disorders: Infrequent: purpura, epistaxis, thrombocytopenia; Psychiatrlc Disorders: Infrequent: apathy, paroniria, paranoid reaction, libido increased, delirium; Urinary System Disorders: Frequent: incontinence; Infrequent: hematuria, micturition frequency, cystitis, urinary retention, nocturia, renal calculi.

\section{OVERDOSAGE}

Because strategies for the management of overdose are continually evolving, it is advisable to contact a poison control center to determine the latest recommendations for the management of an overdose of any drug. As in any case of overdose, general supportive measures should be utilized. Signs and symptoms of significant overdosing of galantamine are predicted to be similar to those of overdosing of other cholinomimetics.

\section{DOSAGE AND ADMINISTRATION}

The dosage of REMINYL ${ }^{\star}$ shown to be effective in controlled clinical trials is $16-32 \mathrm{mg} /$ day given as twice daily dosing. As the dose of $32 \mathrm{mg} /$ day is less well tolerated than lower doses and does not provide increased effectiveness, the recommended dose range is 16-24 mg/day given in a BID regimen. The dose of $24 \mathrm{mg} /$ day did not provide a statistically significant greater clinical benefit than $16 \mathrm{mg} /$ day. It is possible, however, that a daily dose of $24 \mathrm{mg}$ of REMINYL might provide additional benefit for some patients. The recommended starting dose of REMINYL is $4 \mathrm{mg}$ twice a day $(8 \mathrm{mg} /$ day). After a minimum of 4 weeks of treatment, if this dose is well tolerated, the dose should be increased to $8 \mathrm{mg}$ twice a day $(16 \mathrm{mg} /$ day). A further increase to $12 \mathrm{mg}$ twice a day ( $24 \mathrm{mg} /$ day) should be attempted only after a minimum of 4 weeks at the previous dose. REMINYL should be administered twice a day, preterably with morning and evening meals. If therapy has been interrupted for several days or longer, the patient should be restarted at the lowest dose and the dose escalated to the current dose.

Doses in Special Populations: Galantamine plasma concentrations may be increased in patients with moderate to severe hepatic impairment. In patients with moderately impaired hepatic function (Child-Pugh score of 7-9), the dose should generally not exceed $16 \mathrm{mg}$ day. The use of REMINYL in patients with severe hepatic impairment (Child-Pugh score of 10-15) is not recommended. For patients with moderate renal impairment the dose should generally not exceed $16 \mathrm{mg} / \mathrm{day}$. In patients with severe renal impairment (creatinine clearance $<9 \mathrm{~m} / / \mathrm{min}$ ), the use of REMINYL ${ }^{\oplus}$ is not recommended.

7517303

March 2001, March 2001

US Patent No. 4,663,318

(C) Janssen 2007

Manufactured by:

Janssen-Cilag SpA

Latina, Italy

Distributed by:

Janssen Pharmaceutica Products, L.P. Titusville, NJ 08560

JANSSEN 奥 $\begin{gathered}\text { PHARMACEUTICA } \\ \text { PRODUCTS, L.P. }\end{gathered}$

